\title{
KAJIAN EKSTRAKSI PEKTIN DARI LIMBAH JERUK RIMAU GERGA LEBONG (JERUK RGL) DAN JERUK KALAMANSI
}

\author{
Yessy Rosalina $^{1}$, Laili Susanti ${ }^{1}$ dan Noveriani Br Karo ${ }^{2}$ \\ ${ }^{1)}$ Dosen Jurusan Teknologi Pertanian Universitas Bengkulu \\ ${ }^{2)}$ Alumni Jurusan Teknologi Pertanian Universitas Bengkulu \\ e-mail : yessyrosalina@unib.ac.id
}

\begin{abstract}
ABSTRAK
Salah satu tanaman yang potensial dikembangkan di Propinsi Bengkulu adalah buah jeruk Rimau Gerga Lebong (RGL) dan jeruk Kalamansi. Tanaman buah jeruk Gerga Lebong dan jeruk Kalamansi, merupakan salah satu bahan baku industri pengolahan sirup buah. Limbah yang dihasilkan dari industri ini berupa kulit buah dan kulit+daging buah hasil pengepresan sari buah. Limbah tersebut berpotensi sebagai sumber pektin. Pektin adalah suatu komponen serat yang terdapat pada lapisan lamella tengah dan dinding sel primer pada tanaman. Senyawa-senyawa pektin juga berfungsi sebagai bahan perekat antra dinding sel yang satu dan lainnya (Winarno, 1991). Tujuan penelitian ini adalah untuk melakukan kajian terhadap rendemen dan mutu pektin yang dihasilkan dari limbah jeruk Gerga Lebong dan jeruk Kalamansi. Hasil penelitian menunjukan bahwa rendemen pektin dari limbah Jeruk kalamansi lebih besar dari limbah jeruk Gerga Lebong. Secara berturut-turut rendemen yanga dihasilkan adalah 15,3\% (kulit jeruk kalamansi), 7, $82 \%$ (kulit+daging buah kalamansi), 1,5\% (kulit jeruk Gerga Lebong) dan 0,18 \% (kulit+daging buah jeruk Gerga Lebong). Hasil analisa mutu terhadap variabel Galakturonat menunjukan bahwa nilai Galakturonat pada kulit jeruk Kalamansi mempunyai nilai tertinggi yaitu 93,51 \%. Analisa terhadap derajat Esterifikasi menunjukan bahwa pektin hasil ekstraksi limbah jeruk Gerga Lebong dan jeruk Kalamansi tergolong pada pektin bermetoksil rendah, dengan nilai derajat esterifikasi pada kisaran 13,7720,83 .
\end{abstract}

Kata kunci : jeruk RGL, jeruk Kalamansi, rendemen, mutu, pektin

\section{PENDAHULUAN}

Jeruk Rimau Gerga Lebong (Jeruk RGL) dan Jeruk Kalamansi merupakan salah satu produk pertanian potensial di Propinsi Bengkulu. Kedua jenis jeruk tersebut merupakan bahan baku utama pada industri olahan sirup buah di Kota Bengkulu. Industri pengolahan sirup buah ini menghasilkan limbah berupa kulit dan kulit+daging buah hasil pengepresan buah. Salah satu komponen yang terdapat di dalam jaringan kulit buah adalah pektin. Pektin merupakan suatu komponen serat yang terdapat pada lapisan lamella tengah dan dinding sel primer pada tanaman. Senyawa pektin juga berfungsi sebagai bahan perekat antara dinding sel satu dengan dinding sel lainnya (Winarno, 1991). Pada dasarnya semua tanaman yang berfotosintesis tanpa kecuali mengandung pektin namun dalam jumlah yang berbeda tergantung pada jenis tanaman dan tingkat kematangannya (Irza, 2015). Pektin merupakan komponen dari jaringan tanaman yang dimanfaatkan secara luas dalam industri makanan. Penggunaan pektin digunakan sebagai bahan penstabil pada sari buah, bahan pembuatan jelly, jam dan marmalade.

Menurut Andreas (2012) dalam jaringan tanaman pektin berada sebagai protopektin yang bersifat tidak larut dalam air karena berada sebagai garam kalsium dan magnesium. Metode yang digunakan untuk mengekstrak pektn dari jaringan tanaman sangat beragam. Akan tetapi, pada umumnya ekstraksi pektin dilakukan dengan menggunakan ekstraksi asam. Beberapa jenis asam yang dapat digunakan dari ekstraksi pektin menurut Hariyati (2006) adalah asam tartrat, asam malat, asam sitrat, asam laktat, 
asam asetat, asam fosfta, tetapi ada cenderung menggunakan air mineral yang murah seperti asam sulfat, asam klorida, dan asam nitrat.

Penelitian Muliyah (2016) memperoleh hasil bahwa perlakuan terbaik pada pektin hasil ekstraksi limbah jeruk pontianak (Citrus nobilis var microcarpa) dengan suhu $95^{\circ} \mathrm{C}$, waktu 40 menit, pelarut asam klorida. Pelarut $\mathrm{HCl}$ juga memberikan hasil terbaik pada proses ekstraksi pektin dari kulit lemon (Citrus medica) pada suhu $80^{\circ} \mathrm{C}$ selama 45 menit (Hesti, 2013). Proses ekstraksi pektin dari kulit jeruk bali (Citrus Maxima) dengan pelarut asam klorida memberikan rendemen lebih besar jika dibandingkan dengan pelarut asam asetat (Andareas, 2015). Selain jenis pelarut, faktor-faktor yang lain berpengaruh pada proses ekstraksi adalah perlakuan pendahuluan bahan sebelum ekstraksi, ukuran partikel, jenis pelarut, waktu, suhu dan proses pemisahan pelarut (Kawiji, 2015).

Luasnya pemanfaatan pektin, tersedianya bahan baku yang cukup dan teknik ekstraksi yang sederhana maka perlu dilakukan kajian terhadap potensi dan kualitas ekstraksi pektin dari limbah jeruk RGL dan jeruk kalamansi. Oleh karena itu, tujuan penelitian ini adalah untuk mendapatkan rendemen dan kualitas pektin dari limbah jeruk RGL dan jeruk kalamansi. Yang dimaksud limbah pada penelitian ini adalah kulit dan kulit+daging buah (limbah pengepresan sari buah). Buah yang digunakan adalah buah jeruk dengan tingkat kematangan siap panen (matang optimal).

\section{METODE}

Penelitian dilaksanakan di Laboratorium Teknologi Pertanian Fakultas Pertanian Universitas Bengkulu pada bulan Januari 2017. Bahan-bahan yang diperlukan untuk penelitian ini adalah jeruk RGL, jeruk kalamansi, Asam Klorida $(\mathrm{HCl}) \quad 0,2 \mathrm{~N}$, aquades, $\mathrm{NaCl}, \mathrm{NaOH} 0,2 \mathrm{~N}$, alkohol $96 \%$. Alat-alat yang dibutuhkan dalam penelitian ini adalah oven, blender, nampan, pisau, talenan, neraca duduk, neraca analitik, kain blacu, gelas ukur, tanur, pipet tetes, kertas saring, gelas beker, buret, indikator universal, cawan krush, termokontrol, erlenmeyer, gelas ukur, corong kaca, statif dan klem.

Penelitian dirancang menggunakan Rancangan Acak Lengkap (RAL) dengan dua faktor. Faktor pertama adalah Jenis Jeruk (J) terdiri atas 2 tingkat yaitu jeruk gerga lebong (J1), jeruk kalamansi (J2). Faktor kedua adalah Bahan Baku (K) yaitu Kulit (K1), Kulit+Daging Buah (K2). Masing-masing perlakuan diulang empat kali ulangan (Tabel $1)$.

Tabel 1. Tabel Perlakuan Penelitian

\begin{tabular}{ccc}
\hline Jenis Jeruk & \multicolumn{2}{c}{ Bahan Baku (K) } \\
\cline { 2 - 3 }$(\mathbf{J})$ & Kulit $($ K1) & Kulit + Daging buah (K2) \\
\hline Jeruk RGL (J1) & K1J1 & K1J2 \\
Jeruk Kalamansi (J2) & K2J1 & K2J2 \\
\hline
\end{tabular}




\section{Tahapan Penelitian}

\section{Perlakuan Pendahuluan}

Perlakuan pendahuluan yang

dilakukan terhadap bahan yaitu untuk persiapan sampel diambil buah jeruk selanjutnya jeruk tersebut dibersihkan kemudian dikeringkan dibawah sinar matahari selama 3 hari. Kulit jeruk yang telah kering kemudian dicincang dan dihaluskan.

\section{Ekstraksi Sampel}

Sebanyak 30 gram sampel ditambahkan $900 \mathrm{ml}$ pelarut $\mathrm{HCl} \quad 0,2 \mathrm{~N}$. Kemudian dipanaskan pada suhu yang ditentukan $80^{\circ} \mathrm{C}$ selama 120 menit. Selanjutnya dilakukan penyaringan dengan menggunakan kain blacu atau corong buncher yang telah dilapisi saring dan filtrat diambil. Filtrat ini disebut filtrat pektin (Andreas, 2012).

\section{Pengendapan Pektin}

Filtrat hasil penyaringan dituang kedalam gelas beker. Filtrat didinginkan lalu ditambahkan alkohol $96 \%$ dengan perbandingan volume 1:1 dan diendapkan selama 24 jam. Endapan dipisahkan dari larutan dengan penyaringan menggunakan kertas saring dan dicuci lagi dengan etanol 96\% untuk menghilangkan sisa asam (tanda tidak lagi bereaksi dengan asam adalah ketika air bekas pencucian pektin berwarna merah bila ditetesi phenolftalein) (Andreas, 2012).

\section{Pengeringan Pektin}

Pektin kemudian dikeringkan dalam oven pada temperatur $45^{\circ} \mathrm{C}$ selama 24 jam. Pektin yang telah kering kemudian ditimbang dan dicatat beratnya (Andreas, 2012).

\section{Variabel Pengamatan \\ Rendemen Pektin}

Pektin kering yang diperoleh ditimbang

beratnya untuk diketahui banyaknya pektin yang dapat di ekstraksi.

$$
\begin{aligned}
& \% \text { Rendemen Pektin }= \\
& \frac{\text { berat pektin kering }}{\text { berat bahan baku kering }} \times 100 \%
\end{aligned}
$$

Kadar abu (Sudarmaji, 1997)

0,25 gr sampel ditimbang dalam cawan porselin+ tutup, selanjutnya dimasukkan kedalam tanur pada suhu $600^{\circ} \mathrm{C}$ selama 90 menit. Abu kemudian didinginkan dalam desikator lalu ditimbang untuk mengetahui berat konstan.

$$
\text { kadar abu }(\%)=\frac{\text { gram abu }}{\text { gram sampel }} \times 100 \%
$$

Analisis kadar galakturonat (Andreas, 2012).

Kadar galakturonat dari mili ekivalen $\mathrm{NaOH}$ yang diperoleh dari penentuan $\mathrm{BE}$ (berat ekivalen) dan kandungan metoksil.

$$
\begin{aligned}
& \begin{array}{l}
\text { Galak turonat }(\%)= \\
\text { miliekivalen }(\mathrm{BE}+\text { metoksil }) \times 176 \times 100
\end{array} \\
& \text { bobot sampel (mg) }
\end{aligned}
$$

Dimana angka 176 merupakan berat terendah ekivalen asam pektat.

Derajat Esterifikasi (Andreas, 2012)

Derajat esterifikasi (DE) dari pektin dapat dihitung dengan :

$$
\begin{aligned}
& D E(\%) \\
& =\frac{176 x \% \text { metoksil } x 100}{31 \times \text { kadar galakturonat }}
\end{aligned}
$$

\section{Analisis Data}

Data yang telah terkumpulkan akan disajikan dalam bentuk grafik dan dianalisis secara deskriptif.

\section{HASIL DAN PEMBAHASAN}

Buah jeruk yang digunakan adalah buah jeruk RGL dan jeruk kalamansi siap panen. Tingkat kematangan buah dilihat secara fisk dan kimia yang meliputi : warna kulit, $\mathrm{pH}$, dan total padatan terlarut (TPT). Bahan baku yang digunakan disajikan pada Tabel 2.

Tabel 2. Karakteristik bahan baku penelitian

\begin{tabular}{lcc}
\hline Uraian & Jeruk RGL* & $\begin{array}{c}\text { Jeruk } \\
\text { Kalamansi }\end{array}$ \\
\hline Warna & Hijau & $\begin{array}{c}\text { Hijau } \\
\text { kekuningan }\end{array}$ \\
kulit & kekuningan & 2,5 \\
pH & 4,17 & $56 \%$ \\
TPT & $11^{\circ}$ brix & *
\end{tabular}

\section{Analisis Rendemen}

Rendemen yang diperoleh pada kulit lebih besar jika dibandingkan dengan limbah kulit+daging buah, pada kedua jenis jeruk 
yang diamamati (Gambar 1). Rendemen pektin dari limbah kulit jeruk kalamansi lebih tinggi jika dibandingkan dengan rendemen pektin dari limbah kulit jeruk RGL. Tingginya rendemen pektin pada limbah kulit buah, dikarenakan sifat pektin yang larut dalam air, alkali dan asam oksalat sehingga pektin tersebut ikut terlarut pada saat proses pengepresan buah (Pantastico, 1989).

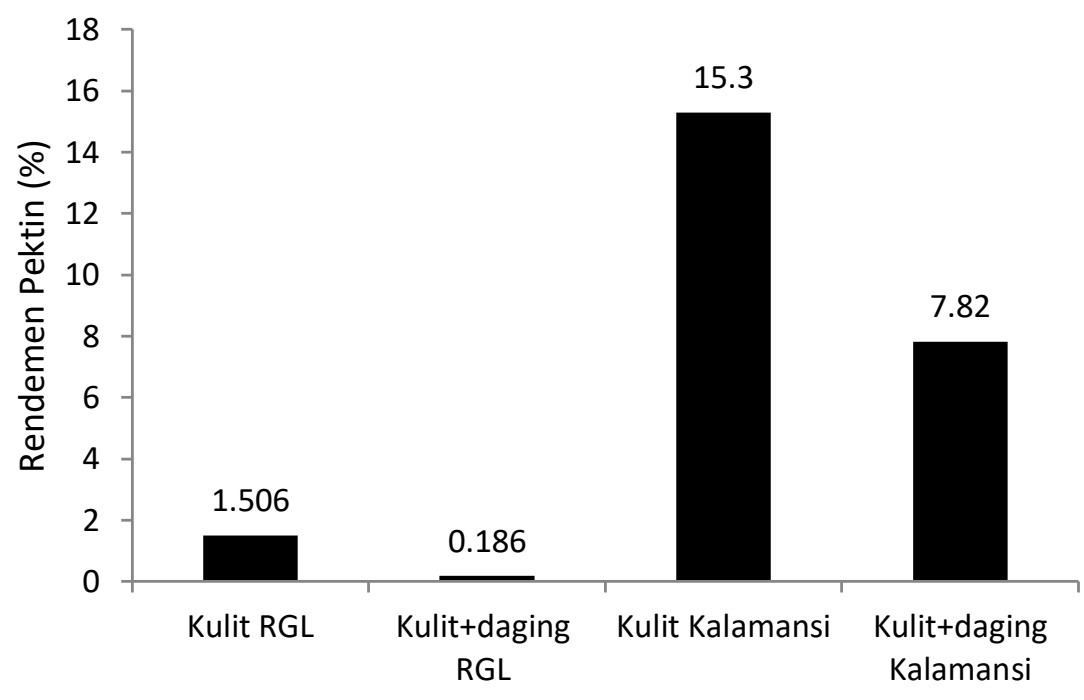

Gambar 1. Rendemen Pektin

\section{Kualitas Pektin}

\section{Kadar Abu}

Kadar abu adalah salah satu parameter mutu pektin yang dihasilkan. Semakin rendah kadar abu, maka mutu pektin semakin meningkat. Hasil analisa menunjukan bahwa kadar abu pada limbah jeruk RGL lebih tinggi dibandingkan dengan kadar abu dari limbah jeruk kalamansi (Gambar 2).

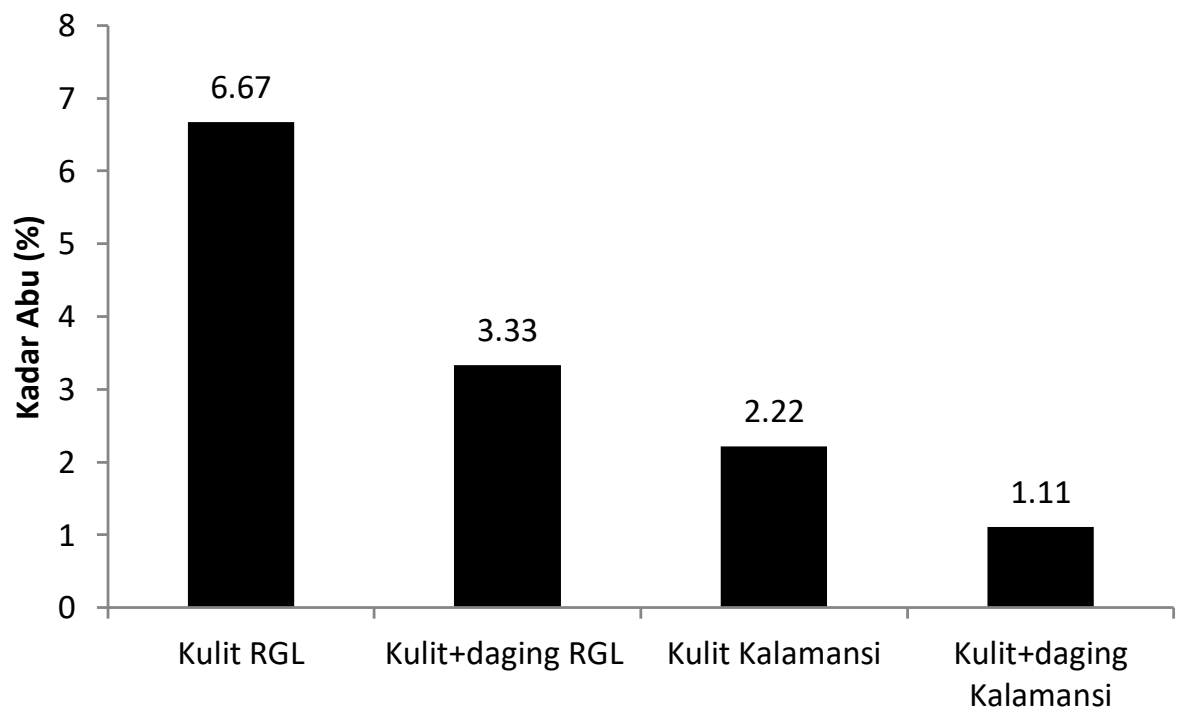

Gambar 2. Kadar Abu Pektin

Kadar abu terendah diperoleh pada perlakukan J2K2 (Limbah Kulit+daging Jeruk Kalamansi) yaitu $1,11 \%$. Tetapi kadar abu pada limbah jeruk kalamansi sesuai dengan peneltian sebelumnya. Penelitian Andreas (2012) ekstraksi pektin dari kulit jeruk bali diperoleh 
kadar abu 3,4\%, sedangkan pada penelitian Hesti (2013) ekstraksi pektin dari kulit jeruk lemon diperoleh kadar abu berkisar antara $0,97 \%-2,25 \%$. Pada penelittian Mauliyah (2016) ekstraksi pektin dari kulit jeruk pontianak diketahui mempunyai kadar abu berkisar antara 0,73-1,33\%. Menurut Kalapathy (2001) kadar abu dalam pektin meningkat seiring meningkatnya kematangan buah $(\mathrm{pH})$ yang digunakan. Hal demikian disebabkan oleh kemampuan asam untuk melarutkan mineral alami dari bahan yang diekstrak. Mineral yang terlarut akan turut mengendap bercampur dengan pektin pada saat proses pengendapan.

\section{Kadar Galakturonat}

Kadar galakturonat menunjukkan kemurnian pektin terhadap bahan organik netral dan lainnya. Estimasi kandungan asam galakturonat sangat penting untuk menentukan kemurnian dan derajat esterifikasi, serta untuk evaluasi sifat fisik dari pektin (Renggana, 1997). Menurut International Pectin Producers Association / IPPA (2002) batas kadar asam galakturonat pada pektin minimal $65 \%$. Nilai galakturinat dari semua perlakuan sudah memenuhi standar IPPA (Gambar 3).

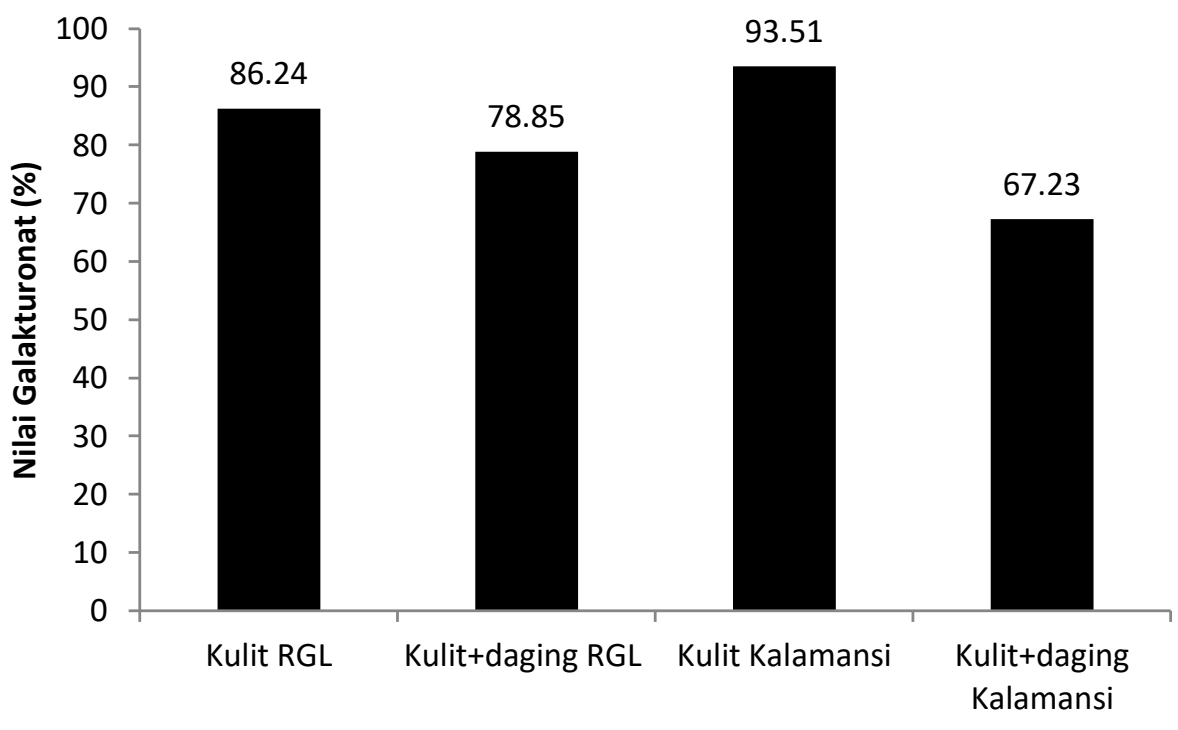

Gambar 3. Kadar Galaturonat

Semakin besar kandungan asam galakturonat maka semakin tinggi kemurnian pektin karena semakin kecil kandungan organik seperti arabinosa, galaktosa dan jenis gula lainnya. Banyaknya kandungan poligalakturonat ini juga berpengaruh dalam pembentukan gel, karena semakin banyak kandungan asam galakturonat maka makin kuat gel yang terbentuk (Andreas dkk, 2012)

\section{Derajat Esterifikasi}

Pada penelitian ini dihasilkan pektin dengan derajat esterifikasi berkisar antara $13,77 \%$ - 20,83\%. Derajat esterifikasi tertinggi terdapat pada perlakuan J2K1 (Kulit Jeruk Kalamasi) yaitu $20,83 \%$, sedangkan derajat esterifikasi terendah terdapat pada perlakuan J2K2 (kulit+daging Jeruk Kalamansi) yaitu 13,77\% (Gambar 4). Menurut IPPA (2002) nilai derajat esterifikasi untuk pektin bermetoksil tinggi memiliki nilai derajat esterifikasi $>50 \%$ dan untuk pektin bermetoksil rendah memiliki nilai $<50 \%$. Pada penelitian ini pektin yang dihasilkan merupakan pektin bermetoksil rendah dan memiliki rentang nilai derajat esterifikasi < $50 \%$. 


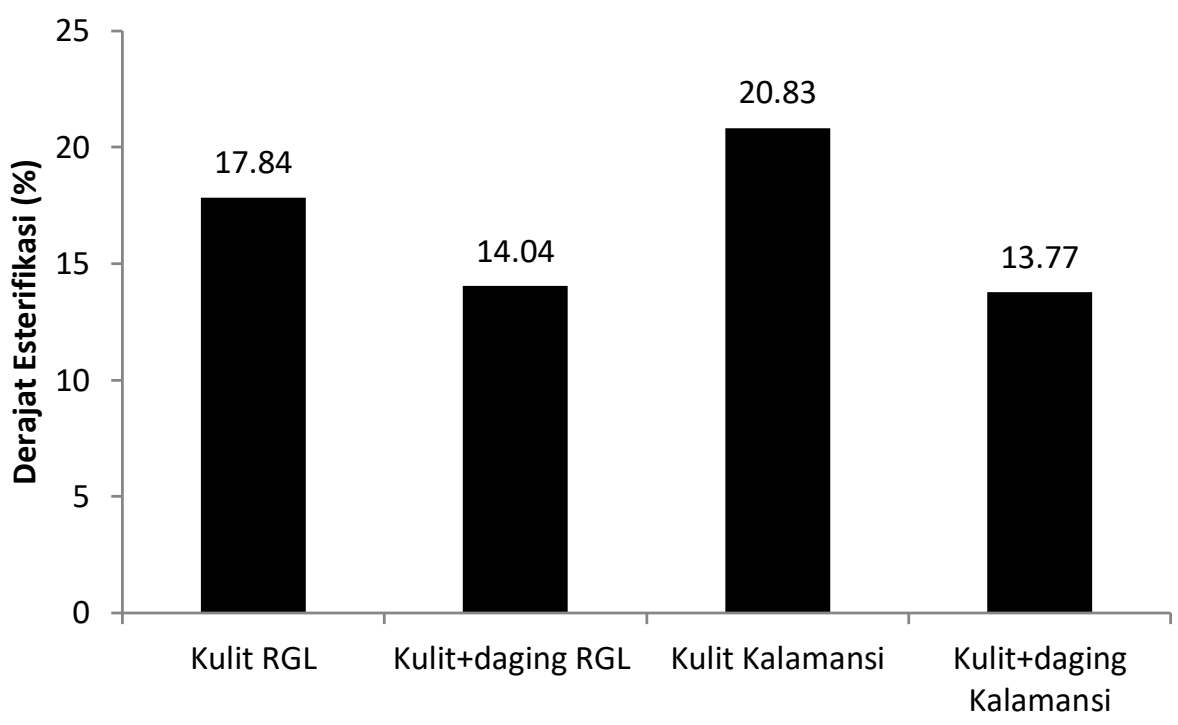

Gambar 4. Derajat Esterifikasi Pektin

\section{KESIMPULAN}

Hasil penelitian didapatkan bahwa rendemen pektin dari limbah Jeruk kalamansi lebih besar dari limbah jeruk Gerga Lebong. Secara berturut-turut rendemen yang dihasilkan adalah 15,3\% (kulit jeruk kalamansi), 7, $82 \%$ (kulit+daging buah kalamansi), 1,5\% (kulit jeruk Gerga Lebong) dan 0,18 \% (kulit+daging buah jeruk Gerga Lebong). Hasil penelitian menunjukkan bahwa Kadar asam galakturonat dan Derajat esterifikasi pektin yang dihasilkan sesuai dengan standar IPPA (International Pectin Producer Association).

\section{DAFTAR PUSTAKA}

Andreas, Agustina, Benyamin. 2012. Pengaruh Waktu, Temperatur dan Jenis Pelarut Terhadap Ekstraksi Pektin dari Kulit Jeruk Bali (Citrus Maxima). Jurnal Teknik Kimia. 4. Vol. 18: 1-8

Hariyati, M.N. 2006. Ekstraksi dan Karakterisasi Pektin dari Limbah Proses Pengolahan Jeruk Pontianak (Citrus Nobilis Var Microcarpa). Institut Pertanian Bogor. Bogor

Hesti dan I. Sailah. 2013. Produksi Pektin dari Kulit Lemon Citrus (Citrus medica).Universitas Syah Kuala Darussalam, Banda Aceh. ISSN 14108720: 117-126.
IPPA (International Pectin Producers Association). 2002. What is Pectin. (http://www.google.com/IPPA.info.htm 1 Diakses pada 20 Maret 2017

Irza M, Kaban, Tarigan, Marrtha, dan Hanun. 2012. Ekstraksi Pektin dari Kulit Pisang Raja (Musa Sapientum). Medan. Jurnal Teknik Kimia. USU Vol 1 (2)

Kalapathy, U. Poctor. 2001. Effect of Acid Extraction and Alcohol Precipitation Conditions on The Yield and Purity of Soy Hull Pectin. Food Chemistry 73: 393- 396

Kawiji, Lia Umi Khasanah, Rohula Utami, dan Novita Try Aryani. 2015. Ekstraksi Maserasi Oleoresin Daun Jeruk Purut (Citrus hytrix DC) Optimasi Rendemen dan Pengujian Karakterikstik Mutu. Jurnal Agritech 35(2):178-183

Muliyah. 2016. Ekstraksi dan Karaterisasi Pektin dari Limbah Proses Pengolahan Jeruk Pontianak (Citrus nobilis var microcarpa). Skripsi. Fakultas Teknologi Pertanian. IPB. Bogor

Pantastico, ER. B. 1989. Fisiologi Pasca Panen. Penanganan dan Pemanfaatan Buah-Buahan dan Sayur-Sayuran Tropika dan Subtropika. Terjemahan oleh: Kamariyani. Gadjah Mada University Press. Yogyakarta.

Sudarmadji, S., B. Haryono dan Suhardi. 1997. Analisis Bahan Makanan dan 
Pertanian. Liberty. Yogyakarta : 97100

Winarno, F.G. 1991. Kimia Pangan dan Gizi. Gramedia Pustaka Utama. Jakarta

Yessy Rosalina, Suprapti Widayati, Asima Rohana dan Joko Prihantoro. 2015. Application of Edible Coating on
Rimau Gerga Lebong (RGL Orange) at Room Temperature Storage (Prosiding), ISBN 9786029071184, Tanggal 13-15 Oktober 2015). 